\title{
Driving sustainability: An analysis of micro-electric vehicle potential and city propensity for their success
}

\author{
Paper 796 \\ Ilona Loustric and Melinda Matyas \\ MaaSLab, University College London, United Kingdom
}

\section{Introduction}

As populations seek to address inherent transport issues, particularly related to climate change and to energy security, two key innovations have risen to the fore: electric vehicles (EVs) and micro-mobility.

\section{Micro-EVs}

Micro-EVs are a subset of both of EVs and micromobility: an innovation that aims to tackle current and future transport and urbanisation issues. They are small electric cars with one or two seats which operate using smaller, but similar, batteries to the EV. Their benefits merge those of EVs and of micro-mobility, presenting a technology that could address almost all current transport issues, particularly in terms of cost and eco-impacts.

The purpose of this paper is to estimate the 'city propensity for success' of micro-EVs in Shanghai and in London via the construction of a composite indicator $(\mathrm{Cl})$ with 16 subcategories. This provides a tool for investors and businesses to utilise in order to maximise the probability of market success of the innovation.

\begin{tabular}{|c|c|}
\hline \multicolumn{2}{|c|}{ Categories } \\
\hline Regulatory quality & Price \\
\hline Rule of Law & Green policies \\
\hline Education & Licenses \\
\hline $\begin{array}{l}\text { Research \& } \\
\text { Development (R\&D) }\end{array}$ & $\begin{array}{l}\text { Ease of license } \\
\text { availability }\end{array}$ \\
\hline EV charging ports & GDP growth rate \\
\hline $\begin{array}{l}\text { Savings from Gasoline } \\
\text { over Electricity }\end{array}$ & Business risk \\
\hline Investment & Country risk \\
\hline Domestic Market Scale & Political risk \\
\hline
\end{tabular}

\section{Data and Methods}

This study built a composite indicator $(\mathrm{Cl})$ or index, following the guidelines of the OECD Handbook for Composite Indicators (2008). Utilising this methodology enables city performance to be ranked and combines aspects of industrial competitiveness, sustainable development, globalisation and innovation, all of which are key for assessing the success of micro-EVs.
The $\mathrm{Cl}$ was built by utilising comparable, wellestablished $\mathrm{Cl}$ models in order to create a credible framework from which to base the research. It focused on 16 subcategories.

The data for each was collected from government papers, existing $\mathrm{Cls}$ and expert sources, using city-specific measures where possible.

The methodology normalised these measures and then weighted and aggregated them in 3 different ways (equal weighting, ranking of subcategories, overarching category performance), giving 3 different results as per the methodology in the image below:

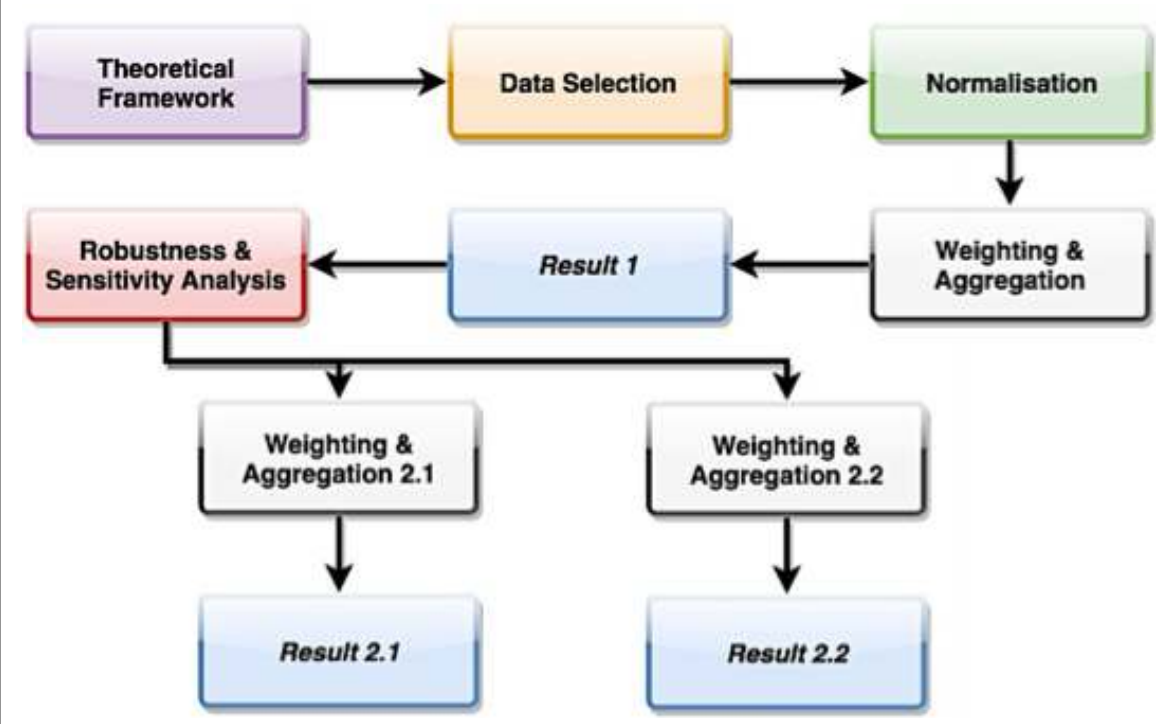

\section{Results}

The normalised index constructed allowed us to compare, temporally and spatially, the propensity for success of Shanghai versus London.

The scores for the equal weighting methodology returned that Shanghai has a higher propensity for success than London.

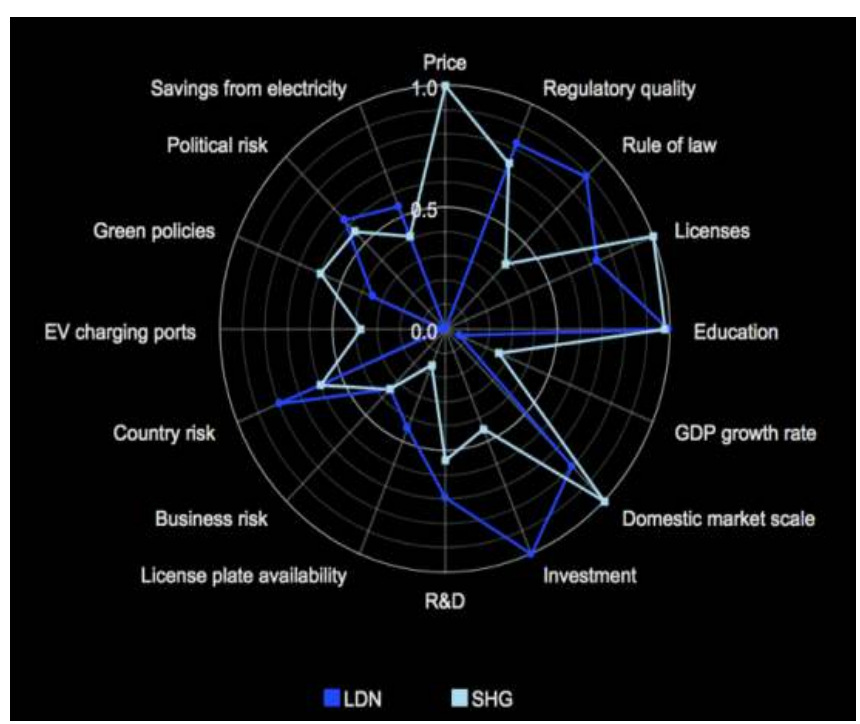

When the subcategories were ranked in order of importance, Shanghai's score remained the same but London's score strongly decreased, suggesting that the former has an $11 \%$ higher propensity for success than the latter.

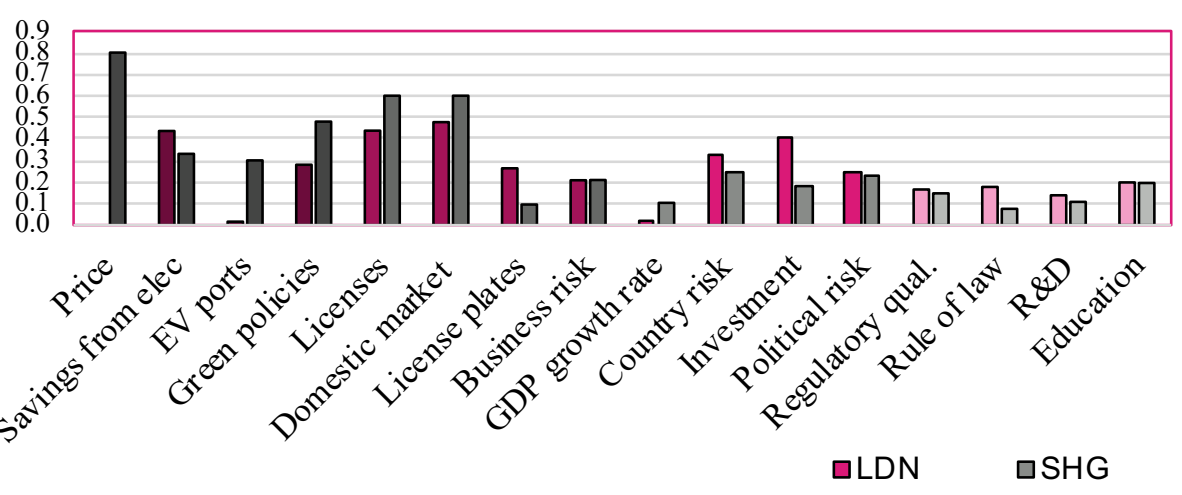

For the final weighting methodology which grouped subcategories in overarching categories, Shanghai again scored higher.

Final Scores

\begin{tabular}{|l|l|}
\hline SHG & LDN \\
\hline 0.587 & 0.570 \\
\hline 0.586 & 0.474 \\
\hline 0.592 & 0.579 \\
\hline
\end{tabular}

\section{Discussion}

This study has explored the fact that micro-EVs are key innovations that could facilitate the decarbonisation of the transport sector. However, in order for innovations like these to succeed despite lock-in, investors and businessmen must look for moments of 'plasticity'. When these systems are more plastic, they may provide 'windows of opportunity' to push the transition.

Furthermore, the study has found that:

- These moments of plasticity occur more frequently and to a higher degree for developing countries, who can 'leapfrog' technologies and thus more easily implement innovations such as the micro-EV,

- This could explain why Shanghai appears to have a higher propensity for success for micro-EVs than London,

- And finally, this transition can be achieved by augmenting the direct benefits to the consumer to incentivise micro-EV innovations as the present-day best possible solution. 